\title{
Planejamento de uma sequência didática sobre energia elétrica na perspectiva CTS
}

\author{
Planning a didactic sequence on electric power \\ from the perspective of STS
}

\author{
Marcello Henrique da Silva Cavalcanti ${ }^{1}$ https://orcid.org/0000-0002-1597-2502 \\ Matheus Marques Ribeiro ${ }^{1}$ • https://orcid.org/0000-0003-0269-204X \\ Mario Roberto Barro ${ }^{1}$ • https://orcid.org/0000-0003-1109-8309
}

\begin{abstract}
Resumo: Planejamos uma sequência didática, relacionando as dimensões epistêmica e pedagógica com os pressupostos Ciência, Tecnologia e Sociedade (CTS). Definimos a energia elétrica como temática, devido à importância da Usina Hidrelétrica de Furnas como matriz energética da região sul de Minas Gerais, estando relacionada à realidade dos alunos dessa região, e sendo pouco explorada em planejamentos de ensino. Estabelecemos as dificuldades no processo de ensino e aprendizagem, e definimos os recursos e estratégias de ensino para melhor compreensão dos conteúdos. Consideramos que as dimensões epistêmica e pedagógica podem ampliar a percepção do professor sobre a temática proposta e promover interações que favorecem a tomada de decisão por meio de ações que permitam refletir a temática na perspectiva CTS. Assim, a sequência didática descrita pode proporcionar ao professor uma melhor percepção de ensino, explorando conceitos científicos a partir de temáticas relacionadas ao cotidiano dos alunos.
\end{abstract}

Palavras-chave: CTS. Sequência didática. Energia elétrica.

\begin{abstract}
In this work, a didactic sequence was planned by linking the epistemological and pedagogical dimensions to Science, Technology and Society (STS) assumptions.. Electric power was defined as a theme due to the importance of the Furnas Hydroelectric Plant as energy matrix in the south of Minas Gerais (Brazil) which is part of the reality of students from this region. The difficulties of the teaching and learning process were established as well as the resources and strategies of teaching were defined in order to enhance the understanding of contents. It was considered that dimensions may widen the perception by the teacher about the theme and promote interactions which benefit the taking of decisions that enable reflection about the theme from the perspective of STS. Thus, the didactic sequence described might provide a better perception of teaching to the teacher who can explore scientific concepts from the theme related to the daily life of students.
\end{abstract}

Keywords: STS. Didactic sequence. Electric power.

\footnotetext{
${ }^{1}$ Universidade Federal de Alfenas (UNIFAL), Instituto de Química, Alfenas, MG, Brasil. E-mail: $<$ marcellohscavalcanti@hotmail.com>.
} 


\section{Introdução}

O planejamento escolar pressupõe uma esfera colaborativa que correlacione as políticas educacionais nacionais, os projetos político-pedagógicos, as experiências de aprendizagem oferecidas nos diversos componentes curriculares, e o planejamento de ensino, que trata do processo de tomada de decisões, principalmente pelos professores, visando a elaboração de ações que contribuam para o processo de ensino e aprendizagem (SANT'ANNA et al., 1995; VASCONCELLOS, 1995).

A partir dessa perspectiva, percebemos que atualmente as transformações sociais decorrentes do desenvolvimento científico e tecnológico e os seus impactos são ignorados nos planejamentos de ensino que não abordam questões de cunho científico, tecnológico e social, assim, reduzindo a educação básica ao ensino de conteúdos fragmentados.

Visando a superação da fragmentação do conteúdo, os Parâmetros Curriculares Nacionais do Ensino Médio (PCNEM) preveem que os conhecimentos de várias disciplinas podem ser utilizados em conjunto para a resolução de problemas concretos, vivenciados pelos alunos, auxiliando na compreensão de fenômenos sob os diferentes pontos de vista, priorizando o pensamento crítico e o desenvolvimento da autonomia do aluno (BRASIL, 2000).

Nesse sentido, a utilização de sequências didáticas, compreendidas como planejamentos de ensino elaborados por etapas, que abordam temáticas que contemplam conteúdos de diversas disciplinas, considerando os aspectos pedagógicos relativos ao ensino e aprendizagem pode ser uma maneira de minimizar a fragmentação do conteúdo.

A sequência didática pode ser utilizada como uma atividade de ensino e de aprendizagem, na qual pode ser fomentada uma discussão com os alunos sobre uma problemática socialmente difundida (MÉHEUT; PSILLOS, 2004). Dessa forma, o aluno é desafiado a buscar argumentos embasados em conteúdos técnicos, científicos e sociais para a sua resolução.

Portanto, neste trabalho, propomos um planejamento de uma sequência didática sobre energia elétrica na perspectiva Ciência, Tecnologia e Sociedade (CTS). Logo, pretendemos relacionar os pressupostos CTS com os aspectos epistêmicos e pedagógicos da sequência didática, de modo a favorecer a tomada de decisão, a criticidade, os aspectos éticos e sociais em discussões que permitam ao professor e aos alunos refletirem e explorarem conceitos científicos a partir dessa temática relacionada ao cotidiano.

Nessa abordagem, os aspectos da Química e da Física, relacionados ao processo de produção e de armazenamento de energia elétrica, junto à necessidade de desenvolvimento de novas tecnologias sustentáveis para suprir a demanda energética crescente, possibilita discussões sobre os principais impactos causados na sociedade e no ambiente, contribuindo para a formação de indivíduos mais críticos.

\section{A sequência didática no ensino de ciências}

Desde 1980, pesquisadores vêm desenvolvendo vários tipos de atividades inspiradas em novas abordagens para aperfeiçoar a compreensão e aproximar os alunos do conhecimento científico. Uma dessas abordagens envolve a implementação de currículos de curta duração orientados a partir de temáticas, que ao todo constituem uma sequência didática (MÉHEUT; PSILLOS, 2004). 
As sequências didáticas são planejamentos de ensino constituintes do processo educativo que possuem várias definições presentes na literatura. Algumas linhas teóricas de elaboração e validação de sequências didáticas utilizadas no ensino de ciências são: a Engenharia Didática (DOUADY; ARTIGUE; COMITI, 1987), que destaca a importância de uma análise epistêmica a priori do tema a ser ensinado, a Educational Design Research (PLOMP, 2009), que tem como objetivo gerar soluções para os problemas da prática educacional e avançar o conhecimento sobre as características dessas intervenções (validação de uma teoria) e o Processo EAR (GUIMARÃES; GIORDAN, 2012), que analisa de forma sistemática e consecutiva os elementos que constituem a sequência didática, sua aplicação, seus resultados e sua relação com o planejamento escolar segundo a abordagem sociocultural.

Ainda no ensino de ciências, outra linha teórica de elaboração de sequências didáticas é a Teacher Learning Sequences (MÉHEUT; PSILLOS, 2004), a qual foi adotada neste trabalho por acreditarmos que uma sequência didática deve ser constituída por atividades que enfatizem a integração entre o currículo, o desenvolvimento de habilidades e a construção de conhecimentos dos alunos, de modo a aperfeiçoar o processo de ensino e aprendizagem.

O termo sequência didática foi introduzido nos anos 2000, denotando a ligação estreita entre os conhecimentos epistemológico e pedagógico, tendo como uma característica a elaboração de uma sequência orientada nas dificuldades de ensino e aprendizagem relatadas na literatura, confrontado com a realidade local da sala de aula (MÉHEUT; PSILLOS, 2001).

No ponto de vista de Méheut (2005), algumas abordagens podem ser adotadas no planejamento das sequências didáticas e, para tal, a autora propõe um modelo que define quatro segmentos básicos: professor, aluno, mundo material e conhecimento científico.

A Figura 1 apresenta o modelo proposto por Méheut e Psillos (2004) para descrever a concepção de uma sequência didática, denominado de "losango didático". Podemos observar, nesse modelo, que a elaboração das sequências didáticas envolve duas dimensões: a dimensão epistêmica e a dimensão pedagógica.

Figura 1. "Losango didático" que representa a concepção de uma sequência didática

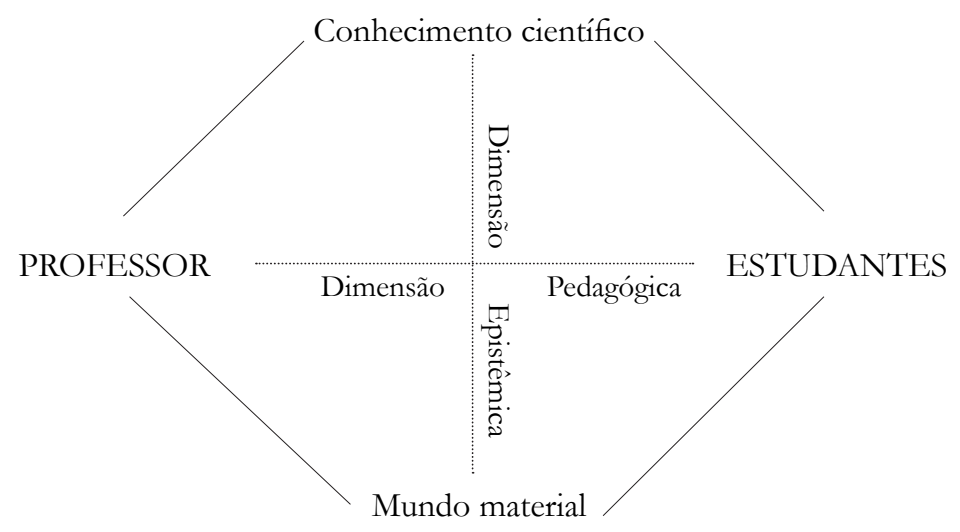

Fonte: adaptado de Méheut e Psillos (2004). 
$\mathrm{Na}$ dimensão epistêmica são considerados os processos de elaboração, de execução e de validação do conhecimento científico, que possuem relação com o mundo material. $\mathrm{Na}$ dimensão pedagógica são considerados os aspectos inerentes ao papel do professor, as interações professor-aluno e aluno-aluno.

\section{A perspectiva CTS no ensino de ciências}

Desde 1970 uma nova perspectiva educacional vem ganhando notoriedade, pois tem buscado contemplar a participação do estudante em discussões de temas que envolvem ciência, tecnologia e sociedade.

O ensino CTS tem como proposta ensinar a partir de situações reais incorporadas a aspectos tecnológicos e sociais dos alunos, de modo a propiciar uma melhor compreensão das experiências cotidianas, favorecendo a integração entre as percepções pessoais dos estudantes com o ambiente científico, social e tecnológico. Tem-se como expectativa desse movimento gerar uma aquisição de conhecimentos sobre a ciência e a tecnologia visando às preocupações cívicas e perspectivas culturais, ao desenvolvimento de habilidades de aprendizagem, tais como: o método de investigação científico para coleta de informações; a resolução de problemas e tomada de decisão; o desenvolvimento de valores e ideias que lidam com as interações entre a ciência, tecnologia e sociedade para a elucidação de questões envolvendo políticas públicas locais e globais. Entretanto, é importante tomar consciência de que a abordagem CTS se preocupa em preparar os estudantes para os próximos níveis educacionais, porém, sem dar forte ênfase nesse aspecto, tendo uma maior preocupação com a formação dos cidadãos que precisam de uma capacitação intelectual para participarem pensativamente da sociedade (BYBEE, 1985).

Desse modo, segundo Aikenhead (1994), o ensino CTS pode ser organizado em uma sequência de eventos que favoreça o entendimento dessa abordagem. O ensino CTS deve iniciar-se no campo da sociedade com uma proposta social chave que ocasione o desenvolvimento de conhecimentos tecnológicos em função das necessidades de se compreender os problemas sociais. Consequentemente, a junção entre sociedade e tecnologia cria a necessidade de compreendermos os aspectos científicos que possibilitam ao final do processo retornar ao domínio da sociedade em condições de tomar decisões, tendo como fundamentos uma compreensão aprofundada da ciência e uma compreensão relevante da tecnologia, além de consciência éticosocial do tema trabalhado.

Logo, o ensino CTS apresenta a imagem do conhecimento socialmente construído. A abordagem orientada para o aluno enfatiza os fatos, habilidades e conceitos básicos da ciência tradicional, mas faz isso integrando esse conteúdo em contextos sociais e tecnológicos significativos para os alunos. Assim, uma boa educação CTS é relevante, desafiadora, realista e rigorosa, visando à participação do cidadão em discussões cada vez mais moldadas por pesquisas e por desenvolvimento, com envolvimento de ciência e tecnologia (AIKENHEAD, 1994).

\section{Elaboração da sequência didática}

Definimos que para elaborarmos uma sequência didática que possibilitasse a união dos preceitos da abordagem CTS com o referencial de sequência didática, de acordo com o modelo 
de Méheut e Psillos (2004), deveríamos propor uma temática relevante e pertencente à realidade local dos alunos, considerando-se os aspectos epistêmicos e pedagógicos relacionados a essa temática, potencializando uma interação maior entre professor e aluno.

Dessa forma, para o planejamento da sequência didática, foi necessário elencar relações que possibilitassem simultaneamente contemplar os pressupostos CTS, tais como: favorecer a tomada de decisão, a criticidade e os aspectos éticos e sociais.

Assim, focalizamos a temática deste trabalho na energia elétrica, devido à importância de se discutir sobre a produção e o consumo da energia elétrica na região do Sul de Minas Gerais, pois se trata de um assunto diretamente relacionado à realidade regional dos alunos e pouco explorado pelos professores.

Dessa maneira, estabelecemos a sequência didática envolvendo três aulas, com os seguintes temas: Energia, Industrialização e Sociedade; Produção de Energia Elétrica no Sul de Minas Gerais e Armazenamento de Energia: Efeitos Ambientais, com suas dimensões Epistêmicas e Pedagógicas.

Para o planejamento dessa sequência didática, a dimensão epistêmica foi descrita levando-se em consideração as dificuldades no processo de ensino e de aprendizagem dos conteúdos físicos e químicos; a relação dos conteúdos propostos com o intuito de aproximar o conhecimento científico da realidade dos alunos e os problemas ético-sociais e ambientais relacionados aos conteúdos com o propósito de favorecer uma formação para a cidadania. Nessa dimensão, buscamos responder as seguintes questões: qual a importância desse conteúdo para os alunos e como esse conteúdo deve ser apresentado aos alunos? Logo, na dimensão pedagógica foram abordadas as potencialidades dos recursos e as estratégias de ensino que podem ser utilizados pelo professor para auxiliar na compreensão dos alunos sobre os conteúdos definidos na dimensão epistêmica.

\section{Proposta de Sequência Didática sobre a temática Energia Elétrica}

A educação CTS centrada no desenvolvimento de percepções sobre um determinado tema social que apresente os conteúdos científicos relacionados ao assunto permite ao professor elaborar suas aulas de maneira a expandir, para além das fronteiras de sua área de formação, problemáticas que sejam singulares à nossa realidade, potencializando a aprendizagem dos alunos.

Essa concepção é pautada no pensamento de que, para compreender as novas demandas educacionais é preciso argumentar sobre o sentido em que a escola deve ser transformada, de modo que os temas tratados não sejam apenas ilustrativos e explorados esporadicamente, mas tratados como conteúdos com um conjunto de informações e de questões que levem a uma formação para a cidadania, vinculando os aspectos sociocientíficos à vida dos alunos (SANTOS et al., 2007).

Nesse sentido, descrevemos em cada aula uma série de argumentos que colaboram para a elaboração do plano de ensino, visando atender a fundamentação teórica adotada neste trabalho. Dessa maneira, apresentamos no quadro 1, de forma resumida, as relações que nortearam a elaboração das dimensões epistêmicas e pedagógicas da sequência didática proposta. 
Quadro 1. Organização da sequência didática sobre energia elétrica

\begin{tabular}{|l|l|l|l|l|}
\hline \multicolumn{1}{|c|}{$\begin{array}{c}\text { Sequência } \\
\text { Didática }\end{array}$} & \multicolumn{3}{c|}{ Dimensão Epistêmica } & \multicolumn{1}{c|}{$\begin{array}{c}\text { Dimensão } \\
\text { Pedagógica }\end{array}$} \\
\hline Aula & Problemática & Objetivos & Conteúdo & Recursos e Estratégias \\
\hline $\begin{array}{l}\text { 1. Energia, } \\
\text { Industrialização } \\
\text { e Sociedade }\end{array}$ & $\begin{array}{l}\text { O aumento } \\
\text { da demanda } \\
\text { energética no } \\
\text { Brasil }\end{array}$ & $\begin{array}{l}\text { Debater as } \\
\text { implicações do } \\
\text { aumento da demanda } \\
\text { de energia elétrica }\end{array}$ & $\begin{array}{l}\text { Inter-relação } \\
\text { entre energia, } \\
\text { industrialização } \\
\text { e sociedade }\end{array}$ & $\begin{array}{l}\text { Apresentação de um } \\
\text { vídeo que contribua } \\
\text { para a compreensão da } \\
\text { problemática inicial }\end{array}$ \\
\hline $\begin{array}{l}\text { 2. Produção de } \\
\text { Energia Elétrica } \\
\text { no Sul de Minas } \\
\text { Gerais-MG }\end{array}$ & $\begin{array}{l}\text { Os impactos } \\
\text { socioambientais } \\
\text { da produção de } \\
\text { energia elétrica } \\
\text { no Sul de Minas } \\
\text { Gerais }\end{array}$ & $\begin{array}{l}\text { Comparar os } \\
\text { impactos de usinas } \\
\text { hidroelétricas com } \\
\text { outras formas } \\
\text { de produção de } \\
\text { energia elétrica e } \\
\text { compreender o } \\
\text { funcionamento de } \\
\text { um circuito elétrico }\end{array}$ & Eletrodinâmica & $\begin{array}{l}\text { Uso de um simulador } \\
\text { computacional } \\
\text { para auxiliar na } \\
\text { compreensão dos } \\
\text { componentes de um } \\
\text { circuito elétrico }\end{array}$ \\
\hline $\begin{array}{l}\text { 3. } \\
\text { Armazenamento } \\
\text { de Energia: } \\
\text { Efeitos } \\
\text { Ambientais }\end{array}$ & $\begin{array}{l}\text { O descarte de } \\
\text { dispositivos de } \\
\text { armazenamento } \\
\text { de energia } \\
\text { elétrica }\end{array}$ & $\begin{array}{l}\text { Explanar o } \\
\text { funcionamento das } \\
\text { pilhas e os riscos do } \\
\text { descarte indevido }\end{array}$ & $\begin{array}{l}\text { Reações de } \\
\text { oxirredução }\end{array}$ & $\begin{array}{l}\text { Utilizar a } \\
\text { experimentação } \\
\text { investigativa } \\
\text { como ferramenta } \\
\text { para propiciar a } \\
\text { cooperação entre os } \\
\text { alunos, de maneira } \\
\text { a compreender as } \\
\text { reações redox }\end{array}$ \\
\hline
\end{tabular}

Fonte: elaborado pelos autores.

\section{Aula 1 - Energia, Industrialização e Sociedade}

\section{Dimensão Epistêmica (Aula 1)}

Na segunda metade do século XVIII, um conjunto de transformações econômicas, sociais e tecnológicas ocasionou mudanças em diversos países da Europa, alterando definitivamente as relações entre as sociedades humanas. Uma das consequências dessas transformações foi o surgimento das indústrias que impulsionaram o desenvolvimento de novas tecnologias, sendo a energia elétrica considerada um marco do processo de industrialização, possibilitando uma aceleração nos mais diversos campos do conhecimento. No entanto, no início do século XX a expansão industrial ocasionou um aumento da demanda de energia elétrica. E essa situação permanece em constante crescimento ao passo que a sociedade se desenvolve (SIMABUKULO et al., 2006).

Segundo a Fundação Getúlio Vargas (2014), o Brasil possui alguns dilemas em termos de oferta de energia. Dentre os desafios a serem debatidos pela sociedade brasileira se 
destacam: a expansão da produção hidrelétrica; como impulsionar de forma efetiva o uso de fontes renováveis; como garantir o desenvolvimento seguro, do ponto de vista tecnológico e ambiental, das reservas do pré-sal; e como impulsionar o mercado de etanol. Todavia, mesmo a matriz nacional sendo considerada limpa por ser concentrada em hidroeletricidade, sofre o ônus de ser um sistema pouco diversificado, com impacto representativo ao meio ambiente.

O plano Nacional de energia (PNE) prevê um incremento da oferta interna de energia de 3,6\% ao ano. Portanto, se faz necessário discutir sobre a diversidade e a disponibilidade de recursos, além das possibilidades de tecnologias. No entanto, o debate sobre a expansão da oferta de energia deve ser feito a partir do entendimento claro dos custos e dos benefícios envolvidos na opção por cada fonte de energia. Apenas a partir da compreensão de tais escolhas pela sociedade é que será possível planejar uma estratégia adequada e consciente para a expansão da matriz energética nacional.

Tais questões são complexas e delicadas, pois há a necessidade de se contemplar os aspectos diretamente ligados à produção de energia limpa sem deixar de levar em conta as externalidades sociais e ambientais, bem como os aspectos relativos ao uso múltiplo dos recursos hídricos. Nesse contexto, a legislação brasileira dispõe de um instrumento de participação da sociedade que pode ser usado a serviço do consenso, ou pelo menos do consentimento que são as audiências públicas (FUNDAÇ̃̃O GETÚLIO VARGAS, 2014).

Portanto, nessa aula, propomos uma discussão com os alunos sobre a importância da energia elétrica no desenvolvimento da sociedade moderna e sua relação com o processo de industrialização. Também sugerimos uma análise da matriz energética brasileira, destacando os dilemas em termos da oferta de energia e as preocupações com o desenvolvimento socioeconômico do país, pois refletir com os alunos sobre a matriz energética nacional é propiciar a aprendizagem de assuntos altamente importantes e determinantes para se projetar as condições futuras enfrentadas pelo cidadão brasileiro, de modo que, será a geração que estamos formando que estará responsável por decidir o futuro da matriz energética brasileira e seus impactos socioeconômicos futuramente.

\section{Dimensão Pedagógica (Aula 1)}

O uso de recursos multimídia possibilita a imersão dos alunos em situações que são difíceis de serem idealizadas. Esses recursos, em especial o vídeo, propicia a aprendizagem múltipla, levando em consideração a sensibilidade, a cultura e as emoções dos alunos. Além disso, auxilia a contextualização de diversos conteúdos (SILVA; OLIVEIRA, 2010).

Para a aula, propomos a utilização de um vídeo que apresenta o desafio de pesquisar novas tecnologias para a produção de energia, de modo a satisfazer a dependência energética do Brasil sem ignorar os impactos sociais e ambientais que poderão ser causados com ações imediatas, sem reflexão. Com isso, utilizaremos um trecho de um vídeo do documentário " $\mathrm{Na}$ Trilha da Energia”, produzido pelo Canal Azul Filmes, onde é exibida a história da primeira usina hidroelétrica no Brasil e são discutidos os possíveis problemas no planejamento energéticos do país. (NA trilha..., 2018).

Com o objetivo de fazer os alunos refletirem sobre esses assuntos, propomos uma aula em que os estudantes possam expor suas questões aos colegas e ao professor, de modo que todos tenham a possibilidade de se posicionar criticamente. Algumas questões a serem discuti- 
das podem estar relacionadas com o processo de planejamento da matriz energética brasileira, com o aumento da demanda energética devido ao consumo inconsciente e com os possíveis problemas econômicos, políticos, ambientais e sociais relacionados.

\section{Aula 2 - Produção de Energia Elétrica no Sul de Minas Gerais}

\section{Dimensão Epistêmica (Aula 2)}

Nesta aula propomos uma discussão que tangencie os impactos sociais e ambientais decorrentes da produção de energia elétrica. Objetivamos estabelecer uma reflexão conjunta, do professor com os alunos, sobre as principais vantagens e desvantagens de cada fonte de energia elétrica.

Como podemos perceber, cada fonte de energia possui vantagens e desvantagens. A produção de energia eólica não emite poluentes, entretanto, sua produtividade é baixa em decorrência de sua dependência com o clima; as usinas nucleares também possuem uma baixa emissão de gases poluentes, porém, demandam um alto custo de construção e a produção de rejeitos radioativos não é um atrativo na perspectiva de se proteger o meio ambiente. Já as usinas termelétricas possuem baixo custo de instalação e grande fonte de combustível, todavia, devese questionar seus altos níveis de emissão de gases atuantes no efeito estufa, devido à poluição do ar dos locais ao redor de sua instalação com elementos que podem gerar as chuvas ácidas e afetar a respiração; por último, as usinas hidrelétricas que são as principais fontes energéticas do Brasil onde a emissão de gases poluentes e seu custo de instalação são baixos, não obstante a devastação da região de represamento do rio é muito grande, modificando tanto o ecossistema quanto a população em seu entorno.

Essa discussão sobre as diversas fontes de obtenção de energia elétrica tem como prerrogativa o questionamento e o posicionamento do aluno com relação às melhores formas de obtenção de energia elétrica, com condições de custo e benefício que visem ao desenvolvimento sustentável para a sociedade. Essa abordagem pode auxiliar os alunos para que em tempos de grandes decisões, tenham condições de analisar esse tipo de situação para além dos seus interesses, corroborando com os preceitos de uma formação mais cidadã.

Com o objetivo de ampliar a discussão sobre a produção de energia elétrica no Brasil, propomos uma análise acerca da construção da Usina Hidroelétrica de Furnas, fonte de energia elétrica da região do Sul de Minas Gerais.

A intenção dessa discussão é gerar argumentos sobre a proposta política do governo que sancionou a construção da usina para aumentar o fornecimento de energia elétrica com o interesse de trazer diversas indústrias multinacionais para o país com a preocupação de desenvolvê-lo economicamente. A instalação de Furnas acometeu em desapropriações de diversas fazendas e até mesmo cidades, além da devastação de uma imensa área florestal para a construção da barragem modificando a fauna e a flora da região. Desse modo, entendemos que é necessário trazer os alunos para uma problemática que afeta diretamente ou indiretamente a todos e, assim, introduzir o conteúdo sobre eletrodinâmica.

Dessa forma, desejamos abordar os conteúdos que compreendemos ser iniciais para a compreensão do tema, tais como: eletrização por contato, modelo de corrente elétrica e circuito elétrico. Com o estudo do modelo de corrente elétrica, objetivamos que os alunos compreendam 
que, independentemente da fonte de produção, a transmissão de energia elétrica é feita a partir de conexões até nossas residências. Contudo, esse movimento se deve à existência de elétrons (cargas negativas), e por uma força eletromotriz induzida (indução de Faraday) que, por uma variação de campo magnético na área que atravessa a bobina ocorre a produção de corrente elétrica alternada que chega até nossas casas. Com a energia elétrica nas residências, os alunos deverão compreender a ocorrência de dissipação (ruptura) de energia nos mais diferentes aparelhos eletrônicos existentes nas residências por meio do conteúdo de circuito elétrico, sendo pretendido que os alunos tomem consciência sobre a fiação elétrica residencial.

Toda essa elaboração visa contemplar aspectos que comparam a realidade dos alunos com as dificuldades no processo de ensino e aprendizagem do conteúdo de eletrodinâmica relatado na literatura. Nesse sentido, o ensino e a aprendizagem sobre eletricidade tem sido objeto de muitas investigações em livros e conferências (DUIT; JUNG; VON RHOENECK, 1985), nos quais, é reportado que raramente o conteúdo de circuito elétrico é aprendido de forma adequada pelos alunos ao final do ensino médio. Esses estudos, em geral, verificam que os alunos encontram grandes dificuldades na compreensão dos conceitos sobre eletrodinâmica e que, habitualmente, essas dificuldades são ignoradas no momento da elaboração das aulas sobre esses conteúdos (PSILLOS, 1998).

Segundo Psillos (1998), os alunos demonstram dificuldades de aprendizagem no que diz respeito à (ao):

1. ligação entre modelos diferentes: os alunos não estabelecem relações entre modelos qualitativos e quantitativos, e entre mecanismos macroscópicos e microscópicos subjacentes;

2. estabelecimento de relações fenomenológicas: os alunos não relacionam fenomenologicamente diferentes áreas de eletrocinética e eletrostática. Para os estudantes, não há características comuns óbvias entre a atração/repulsão de corpos eletrificados e a iluminação de uma lâmpada;

3. desenvolvimento do raciocínio sistêmico: os alunos possuem um raciocínio linear sem fazer relação das partes integrantes do circuito elétrico. Para compreender o conteúdo sobre circuito elétrico, os alunos devem adquirir um raciocínio sistêmico, de que, o circuito elétrico é um sistema fechado, no qual, todos os componentes interagem uns com os outros e qualquer perturbação estende-se em todas as direções.

\section{Dimensão Pedagógica (Aula 2)}

As ferramentas tecnológicas propiciam aos alunos acessar dimensões antes inacessíveis, como os modelos químicos e físicos. Visto que a simulação é um modelo, não conseguimos compreender sem a ajuda dessas tecnologias. No máximo, entendemos sua existência por figuras estáticas em livros didáticos. Nessa perspectiva, os simuladores computacionais são interessantes por promover um dinamismo e uma facilidade na alteração das propriedades que são estudadas, de modo, a favorecer a relação do aluno com o conceito a ser estudado.

Propomos para esta aula a utilização do simulador virtual do Physics Education Technology Project (PhET) na abordagem do conteúdo de eletrodinâmica, relacionando o conceito de corrente elétrica, ligação metálica, estrutura atômica, diferença de potencial, com o cotidiano dos alunos. 
O uso dos simuladores virtuais do PhET como recurso didático no ensino de Física pode contribuir para a aprendizagem dos conteúdos físicos, pois age como facilitador e motivador no processo de ensino e de aprendizagem. Busca-se colocar o estudante mais ativo no processo de ensino de forma que: observe os modelos físicos; avance na construção de conceitos, leis e teorias; colete os dados das simulações; elabore hipóteses e teste a validade das mesmas; confronte o seu conhecimento prévio com o conhecimento científico; questione e estabeleça relações entre a teoria e prática na compreensão dos fenômenos físicos presentes no seu dia a dia (CARRARO; PEREIRA, 2014).

Cabe destacar que todos esses conceitos devem ser estudados a partir da construção de circuitos elétricos elaborados virtualmente por cada um dos alunos a partir de suas concepções. Ao término desse momento, sugere-se que o professor projete cada um dos circuitos elaborados e discuta com a turma os acertos e os erros de cada sistema, modificando-os em tempo real, demonstrando as diversas possibilidades de construção do circuito e as potencialidades do software.

Contudo, objetivamos que os alunos participem ativamente de suas aprendizagens, por meio da promoção de uma discussão entre os alunos e o professor e sobre as diferentes formas de se produzir energia das mais diversas fontes e como estabelecê-las de modo a atender as necessidades de cada aparelho elétrico em nossas casas. Nesse sentido, propomos que o professor coloque em discussão o consumo excessivo e as maneiras de otimizar uma produção energética mais limpa e de minimizar o impacto socioambiental dessas fontes.

\section{Aula 3 - Armazenamento de Energia: Efeitos Ambientais}

\section{Dimensão Epistêmica (Aula 3)}

A partir de 1990, com o surgimento da internet, testemunhamos um grande progresso na construção de aparelhos eletroeletrônicos portáteis, tais como: computadores, câmeras fotográficas e principalmente os celulares. Concomitantemente, aumentou-se a requisição de pilhas e de baterias em escalas cada vez menores para atender à demanda de produtos eletrônicos de fácil locomobilidade e de alto desempenho. Todavia, o mercado nos oferece uma vasta gama de pilhas e baterias que atendem a uma série de instrumentos, sendo uma das mais importantes a utilização da bateria de lítio em celulares e baterias de chumbo-ácido nos automóveis. $\mathrm{O}$ conhecimento sobre o funcionamento dessas tecnologias tem grande importância para que se possa planejar as novas tecnologias que ainda estão por vir.

Por outro lado, dado que algumas das pilhas e baterias disponíveis no mercado usam materiais tóxicos, muitos países, inclusive o Brasil, têm se preocupado com os riscos à saúde humana e ao meio ambiente que estes sistemas eletroquímicos apresentam. Neste sentido, o Conselho Nacional do Meio Ambiente (CONAMA) publicou no Diário Oficial da União de 22 de julho de 1999 a Resolução no 257, disciplinando o descarte e o gerenciamento ambientalmente adequado de pilhas e baterias usadas, no que tange à coleta, reutilização, reciclagem, tratamento ou disposição final (BOCCHIN; FERRACIN; BIAGGIO, 2000).

Considerando-se toda a problemática exposta, nesta aula, temos como objetivo discutir com os alunos as maneiras mais adequadas de se descartar esses materiais, visando a uma amenização de seus impactos ambientais. Sobre esse ponto de vista, é proposto que os alunos 
reconheçam que as pilhas e as baterias são potenciais poluidores do solo e da água, levando a sociedade a sofrer uma possível contaminação na agricultura por metais pesados e uma contaminação dos lençóis freáticos por líquidos tóxicos, tais como: mercúrio, ácido sulfúrico e chumbo. Com esta aula, pretendemos possibilitar aos alunos uma reflexão sobre o melhor modelo para que se possa amenizar os efeitos do descarte de pilhas e de baterias no meio ambiental por meio do estudo dos diferentes tipos de pilhas e suas composições.

Nas pilhas chamadas comuns, ocorrem reações envolvendo zinco metálico $\left(\mathrm{Zn}^{0}\right)$, óxido de manganês $\left(\mathrm{MnO}_{2}\right)$ e amônio $\left(\mathrm{NH}_{4}^{+}\right)$que reagem formando como produtos óxido mangânico $\left(\mathrm{Mn}_{2} \mathrm{O}_{3}\right)$ e amônia $\left(\mathrm{NH}_{3}\right)$. Já na bateria dos carros, por exemplo, chamada bateria ácido-chumbo ocorre uma reação entre chumbo metálico $\left(\mathrm{Pb}^{0}\right)$, óxido de chumbo $\left(\mathrm{PbO}_{2}\right)$ e ácido sulfúrico $\left(\mathrm{H}_{2} \mathrm{SO}_{4}\right)$, que ao reagir forma sulfato de chumbo $\left(\mathrm{PbSO}_{4}\right)$. O descaso e a falta de políticas para tratar desse assunto podem ocasionar situações em que, por exemplo, o zinco em concentrações excessivas no solo, pode ser assimilado pelas plantas, produzindo efeitos nocivos às próprias plantas e também à dieta humana (MUNIZ et al., 1996). O chumbo pode contaminar uma grande área, sendo encontrado em diversos materiais que utilizamos no cotidiano como, por exemplo, em processos de extração mineral, em fabricação de plásticos, operação de corte e solda de peças e chapas metálicas contendo chumbo, tinturas de cabelo, fabricação caseira de “chumbadas" de pesca e cartuchos (CAPITANI; PAOLIELLO; ALMEIDA, 2009).

Assim, com toda essa flutuação de possibilidades é plausível se pensar que a contaminação do meio ambiente em decorrência do descarte de pilhas seja insignificante em comparação com as demais fontes poluidoras. Contudo, se pensarmos que no Brasil são produzidas ao ano cerca de 3 bilhões de unidades entre pilhas e baterias para uso doméstico, tal quantidade gera preocupação, uma vez que é de conhecimento público que a maior parte do lixo doméstico é destinado a lugares inadequados para sua disposição (AGOURAKIS et al., 2006).

Para propiciar a interação dos alunos com essa problemática e a fundamentação científica no desenvolvimento de uma pilha propomos o estudo sobre a percepção e a definição da área que abrange a eletroquímica como uma área da ciência que estuda as transformações da energia química em energia elétrica de diferentes modos; as reações de oxirredução ocorridas nos processos eletroquímicos e relacionar essas reações a partir do funcionamento e das particularidades da pilha de Daniell.

Esses conteúdos devem ser apresentados de modo a tentar contemplar e superar as dificuldades discutidas pela literatura no ensino de processos eletroquímicos. Dentro dessa discussão, os conteúdos envolvendo eletroquímica têm sido frequentemente apontados por professores e estudantes do ensino médio como um dos assuntos que representam grandes dificuldades no processo de ensino e aprendizagem (NIAZ; CHACÓN, 2003). Diversas pesquisas envolvendo concepções alternativas e dificuldades de aprendizagem para essa temática já foram realizadas (BUESO; FURIÓ; MANS, 1988; CAAMAÑO; OÑORBE, 2004; LIN et al., 2002). Os principais resultados encontrados apontam para o fato de que os estudantes têm dificuldades de aprendizagem relativas aos conceitos de oxirredução, de pilhas e de célula eletrolítica.

De acordo com a literatura, as principais dificuldades na aprendizagem do conceito de oxirredução estão na compreensão do processo de oxidação e redução ocorrerem de forma independente (BUESO; FURIÓ; MANS, 1988) e a existência de transferência de moléculas de oxigênio entre as espécies envolvidas (CAAMAÑO; OÑORBE, 2004). Já no conceito de pilha, as dificuldades se apresentam na identificação do ânodo e do cátodo (SANGER; GREENBOWE, 
1997), além da função da ponte salina em proporcionar elétrons para reestabelecer o circuito (CAAMAÑO, OÑORBE, 2004). Além disso, é relatada a dificuldade em compreender que a polaridade dos terminais não tem efeito no ânodo e no cátodo, que na superfície dos eletrodos inertes não ocorre reação, diferença entre a força eletromotriz e a magnitude da voltagem em uma eletrólise e por fim, a diferença entre o potencial da célula eletrolítica e a concentração dos íons. (CAAMAÑO; OÑORBE, 2004; SANGER; GREENBOWE, 1997).

Reforçando esses dados, pesquisas clássicas envolvendo as dificuldades de aprendizagem em eletroquímica, como as de Sanger e Greenbowe (1997) e de Niaz e Chacón (2003), mostraram outras dificuldades mais específicas, tais como: a identificação de onde ocorre a reação na célula eletroquímica; como se dá o processo de fluxo dos elétrons, a condução no eletrólito, a neutralidade elétrica; como são a terminologia e os aspectos relativos aos componentes do processo, tais como: ponte salina, cátodo e ânodo. Além disso, os estudantes têm, ainda, dificuldade para relacionar a deposição e o desgaste do metal com os elétrons recebidos e perdidos no processo.

\section{Dimensão Pedagógica (Aula 3)}

A aproximação entre a experimentação investigativa e o ensino e a aprendizagem na perspectiva CTS convergem para a viabilidade de os alunos resolverem problemas reais. Nesse sentido, o ensino de química, atribuído ao enfoque CTS empregando como estratégia didática a experimentação investigativa colabora para a formação de um cidadão crítico com capacidade de debater sobre ciência, tecnologia e suas consequências sociais.

Os trabalhos em ensino mostram que os estudantes aprendem mais sobre a ciência e desenvolvem cognitivamente melhor seus conhecimentos conceituais em relação às aulas com caráter tradicional, quando participam de investigações científicas semelhantes às feitas nos laboratórios de pesquisa (HODSON, 1994). Conforme Silva (2005), a experimentação investigativa baseada na educação CTS pode desenvolver habilidades nos alunos, tais como: valorização do trabalho em equipe (tomadas de decisões individuais e coletivas para resolução de problemas reais), entendimento sobre a natureza das atividades científicas e tecnológicas (implicações sociais da ciência e tecnologia) e interpretação de texto científico (por meio de busca e análise de informações).

Complementando esse aspecto, Hofstein, Aikenhead e Riquarts (1988) apontam que a ancoragem do enfoque CTS nesse tipo de atividade desenvolve no estudante várias habilidades, tais como: a autoestima, a comunicação escrita e oral, o pensamento lógico para resolver problemas, a tomada de decisão, o aprendizado colaborativo e cooperativo.

Logo, nesta aula propomos uma abordagem investigativa de nível 2, por meio da qual o professor apresenta uma situação-problema e aos grupos de alunos cabem à elaboração de hipóteses, a escolha dos procedimentos experimentais, a coleta e análise dos dados, a elaboração de conclusões e a proposta de soluções para o problema em questão. A experimentação investigativa nível 2 requer habilidades cognitivas de ordens mais altas do que a simples evocação, pois envolvem o reconhecimento da situação problemática, o estabelecimento de relações, visto que, para obter êxito no desenvolvimento da atividade, o estudante precisará mobilizar habilidades, tais como: sequenciar, comparar, contrastar, aplicar leis e conceitos para a resolução do problema (SUART; MARCONDES, 2008). 
Portanto, esse método possibilita uma série de alternativas em relação à questão problema, com base no levantamento de múltiplas hipóteses, conduzindo ao debate e discussão de diferentes análises de um mesmo problema. Por isso, a experimentação investigativa proporciona um ambiente de reflexão e de criatividade, desenvolvendo o trabalho em equipe e um pensamento crítico sobre ciência, tecnologia e sociedade.

\section{Considerações finais}

A partir deste trabalho podemos concluir que refletir sobre as dimensões epistêmica e pedagógica propostas por Méheut e Psillos (2004) favoreceu a elaboração da sequência didática, sobre a temática Energia Elétrica, relacionada aos pressupostos CTS.

Assim, a dimensão epistêmica pode ampliar a percepção do professor sobre a temática proposta, à medida que este começa a relacionar as dificuldades de aprendizagem dos alunos com as descritas na literatura e a questionar, tanto a ciência e tecnologia, quanto à sociedade e ao ambiente. A dimensão pedagógica pode promover interações que favorecem a tomada de decisão na medida em que os recursos e as estratégias escolhidas fomentem discussões que permitam refletir a temática na perspectiva CTS.

Sequências didáticas, na perspectiva CTS, que contemplem as dimensões epistêmicas e pedagógicas relacionadas aos conteúdos curriculares a ser ensinados possibilitam elaborações de planejamentos de ensino alternativos que possam proporcionar ao professor melhor percepção de ensino, explorando conceitos científicos a partir de temáticas relacionadas ao cotidiano dos alunos.

\section{Referências}

AGOURAKIS, D. C. et al. Comportamento de zinco e manganês de pilhas alcalinas em uma coluna de solo. Química Nova, São Paulo, v. 29, n. 5, p. 960-964, 2006. Disponível em: <https:/ /doi.org/10.1590/S0100-40422006000500014>. Acesso em: 8 out. 2018.

AIKENHEAD, G. S. What is STS science teaching? In: SOLOMON, J.; AIKENHEAD, G. S. (Org.). STS education: international perspectives on reform. New York: Teachers College Press, 1994. p. 47-59.

BOCCHIN, N.; FERRACIN, L. C.; BIAGGIO, S. R. Pilhas e baterias: funcionamento e impacto ambiental. Química Nova na Escola, São Paulo, n. 11, p. 3-9, 2000. Disponível em: < http://qnesc.sbq.org.br/online/qnesc11/v11a01.pdf>. Acesso em: 8 out. 2018.

BRASIL. Ministério da Educação. Parâmetros curriculares nacionais para o ensino médio (PCNEM). Brasília, [2000]. Disponível em: <https://tinyurl.com/ya78q4aq>. Acesso em: 8 out. 2018. 
BUESO, A.; FURIÓ, C.; MANS, C. Interpretación de las reacciones de oxidación-reducción por los estudiantes: primeros resultados. Enseñanza de las Ciencias, Barcelona, v. 6, n. 3, p. 244-250, 1988. Disponível em: <https://www.raco.cat/index.php/Ensenanza/article/ view/51101>. Acesso em: 8 out. 2018.

BYBEE, J. L. Morphology: a study of the relation between meaning and form. Amsterdam: John Benjamins, 1985.

CAAMAÑO, A.; OÑORBE, A. La enseñanza y el aprendizaje de la química: conceptos y teorías, dificultades de aprendizaje y replanteamientos curriculares. Alambique: didáctica de las ciencias experimentales, Barcelona, v. 41, n. 1, p. 68-81, 2004.

CAPITANI, E. M.; PAOLIELLO, M. B.; ALMEIDA, G. R. C. Fontes de exposição humana ao chumbo no Brasil. Medicina, Ribeirão Preto, v. 42, n. 3, p. 311-318, 2009. Disponível em: <https://doi.org/10.11606/issn.2176-7262.v42i3p311-318>. Acesso em: 8 out. 2018.

CARRARO, F. L.; PEREIRA, R. F. O uso de simuladores virtuais do Phet como metodologia de ensino de eletrodinâmica. In: OS DESAFIOS da escola pública paranaense na perspectiva do professor PDE: artigos. Curitiba, Secretaria de Estado da Educação, 2014. v. 1. Disponível em: <http://www.diaadiaeducacao.pr.gov.br/portals/cadernospde/ pdebusca/producoes_pde/2014/2014_uem_fis_artigo_francisco_luiz_carraro.pdf $>$. Acesso em: 8 out. 2018.

DOUADY, R.; ARTIGUE, M.; COMITI, C. L'ingenierie didactique: un instrument privilegie pour une prise en compte de la complexité de la classe. In: BERGERON, J. C; HERSCOVICS, N.; KIERAN, C. (Ed.). Proceedings of the eleventh International Conference Psychology of Mathematics Education: PME-XI. Quebec, 1987. v. 3, p. 222-228. Disponível em: < https:/ / files.eric.ed.gov/fulltext/ED383532.pdf>. Acesso em: 8 out. 2018.

DUIT, R.; JUNG, W.; VON RHOENECK, C. Understanding and teaching electricity: a guide to the workshop's papers. In: DUIT, R.; JUNG, W.; VON RHOENECK, C. (Ed.). Aspects of understanding electricity: proceedings of an international workshop. Kiel: Schmidt \& Klaunig, 1985. p. 9-38.

FREIRE, M. S.; SILVA JÚNIOR, C. N.; SILVA, M. G. L. Dificuldades de aprendizagem no ensino de eletroquímica segundo licenciandos de química. In: ENCONTRO NACIONAL DE PESQUISA EM EDUCAÇÃO EM CIÊNCIAS, 8., 2011, Campinas. Atas... São Paulo: Associação Brasileira de Pesquisa em Educação em Ciências, 2011. Disponível em: <http:// www.nutes.ufrj.br/abrapec/viiienpec/resumos/R1150-1.pdf>. Acesso em: 8 out. 2018.

FUNDAÇÃO GETÚLIO VARGAS. Energia e sustentabilidade: desafios do Brasil na expansão da oferta e na gestão de demanda. São Paulo, 2014.

GUIMARÃES, Y. A. F.; GIORDAN, M. Instrumento para construção e validação de sequências didáticas em um curso a distância de formação continuada de professores. In: ENCONTRO NACIONAL DE PESQUISA EM EDUCAÇÃO EM CIÊNCIAS, 8., 2011, Campinas. Atas... São Paulo: ABRAPEC, 2011. Disponível em: <http://abrapecnet.org.br/ atas_enpec/viiienpec/resumos/R0875-2.pdf>. Acesso em: 8 out. 2018. 
HODSON, D. Hacia un enfoque más critíco del trabajo de laboratório. Ensenãnza de las Ciencias, Barcelona, v. 12, n. 3, p. 299-313, 1994. Disponível em: <https:/ /www.raco.cat/ index.php/Ensenanza/article/view/21370/93326>. Acesso em: 8 out. 2018.

HOFSTEIN, A.; AIKENHEAD, G.; RIQUARTS, K. Discussions over STS at the fourth IOSTE symposium. International Journal of Science Education, Abingdon, v. 10, n. 4, p. 357-366, 1988. Disponível em: <https://doi.org/10.1080/0950069880100403 >. Acesso em: 8 out. 2018 .

LIN, H. S. et al. Students' difficulties in learning electrochemistry. Proceedings of the National Science Council, Taipei, v. 12, n. 3, p. 100-105, 2002.

MÉHEUT, M. Teaching-learning sequences tools for learning and/or research. In: BOERSMA, K. et al. (Ed.). Research and quality of science education. Dordrecht: Springer, 2005. p. 195-207.

MÉHEUT, M.; PSILLOS, D. Teaching-learning sequences: aims and tools for science education research. International Journal of Science Education, Abingdon, v. 26, n. 5, p. 515-535, 2004. Disponível em: <https://doi.org/10.1080/09500690310001614762. Acesso em: 8 out. 2018.

MÉHEUT, M.; PSILLOS, D. Two aspects of the relations between research and development. In: PSILLOS, D. (Ed.). Proceedings of the third international conference on science education research in the knowledge based society. Thessaloniki: Art of Text Publications, 2001. v. 2, p. 489-491.

MUNIZ, L. L. F. et al. Retenção de zinco em solos do Vale do Aço mineiro, afetada pela remoção de matéria orgânica, óxido de ferro e óxido de manganês. Química Nova, São Paulo, v. 19, n. 5, p. 464-468, 1996. Disponível em: < http:/ /quimicanova.sbq.org.br/ imagebank/pdf/Vol19No5_464_v19_n5_02.pdf>. Acesso em: 8 out. 2018.

NA trilha da energia. Produção de Canal Azul. [S.1.]: Canal Azul, [2018]. Série documental. Disponível em: <http://www.natrilhadaenergia.com.br/>. Acesso em: 8 out. 2018.

NIAZ, M.; CHACÓN, E. A conceptual change teaching strategy to facilitate high school students' understanding of electrochemistry. Journal of Science Education and Technology, Dordrecht, v. 12, n. 2, p. 129-134, 2003. Disponível em: <https://doi. org/10.1023/A:1023983626388>. Acesso em: 8 out. 2018.

PLOMP, T. Educational design research: an introduction. In: PLOMP, T.; NIEVEEN, N. (Ed.). An introduction to educational design research: proceedings of the seminar conducted at the East China Normal University, Shangai (PR China), November 23-26, 2007. Enschede: SLO-Netherlands Institute for Curriculum Development, 2009. p. 9-35. Disponível em: < https://www.slo.nl/downloads/2009/ Introduction_20to_20education_20design_20research.pdf/download $>$. Acesso em: 8 out. 2018. 
PSILLOS, D. Teaching introductory electricity. In: TIBERGHIEN, A.; JOSSEM, E. L.; BAROJAS, J. (Ed.). Connecting research in physics education with teacher education. [S.1.]: The International Commission on Physics Education, 1998. p. 1-10. Disponível em: <http://www.iupap-icpe.org/publications/teach1/ ConnectingResInPhysEducWith'TeacherEduc_Vol_1.pdf>. Acesso em: 8 out. 2018.

SANGER, M. J.; GREENBOWE, T. J. Common student misconceptions in electrochemistry: galvanic, electrolytic and concentration cells. Journal of Research in Science Teaching, Hoboken, v. 34, n. 4, p. 377-398, 1997.

SANT'ANNA, F. M. et al. Planejamento de ensino e avaliação. Porto Alegre: Sagra Luzzatto, 1995.

SANTOS, W. L. P. et al. Química e sociedade: ensinando química pela construção contextualizada dos conceitos químicos. In: ZANON, L. B.; MALDANER, O. A. (Org.). Fundamentos e propostas de ensino de química para a educação básica no Brasil. Ijuí: Unijuí, 2007. p. 67-87.

SILVA, M. J. Ensino de CTS através de revistas de divulgação científica. 2005. 148 f. Dissertação (Mestrado em Educação Científica e Tecnológica) - Universidade Federal de Santa Catarina, Florianópolis, 2005.

SILVA, R. V.; OLIVEIRA, E. M. As possibilidades do uso do vídeo como recurso de aprendizagem em salas de aulas do $5^{\circ}$ ano. In: ENCONTRO DE PESQUISA EM EDUCAÇÃO DE ALAGOAS, 5., 2010, Maceió. Atas... Alagoas: Universidade Federal de Alagoas, 2010. Disponível em: <http://www.pucrs.br/ciencias/viali/tic_literatura/artigos/ videos/Pereira_Oliveira.pdf>. Acesso em: 8 out. 2018.

SIMABUKULO, L. A. N. et al. Energia, industrialização e modernidade: história social. 2006. Trabalho de conclusão de disciplina (Graduação) - Universidade de São Paulo, São Paulo, 2006. Disponível em: <http://eletromemoria.fflch.usp.br/sites/eletromemoria.fflch. usp.br/files/03.pdf>. Acesso em: 8 out. 2018.

SUART, R. C.; MARCONDES, M. E. R. As habilidades cognitivas manifestadas por alunos do ensino médio de química em uma atividade experimental investigativa. Revista Brasileira de Pesquisa em Educação em Ciências, Belo Horizonte, v. 8, n. 2, p. 1-22, 2008.

Disponível em: < https://seer.ufmg.br/index.php/rbpec/article/view/2221/1620>. Acesso em: 8 out. 2018.

VASCONCELLOS, C. S. Planejamento: plano de ensino-aprendizagem e projeto educativo. São Paulo: Libertad, 1995.

Artigo recebido em 13/03/2018. Aceito em 16/06/2018.

Contato: Universidade Federal de Alfenas, Instituto de Química, Rua

Gabriel Monteiro da Silva, 700, Alfenas, MG, 37130-001, Brazil. 